\title{
Causes of Late Revision Surgery after Bone Cement Augmentation in Osteoporotic Vertebral Compression Fractures
}

\author{
Kee-Yong Ha, Young-Hoon Kim, Dong-Gunn Chang, Il-Nam Son, Ki-Won Kim, Sung-Eun Kim \\ Department of Orthopaedic Surgery, Seoul St. Mary's Hospital, The Catholic University of Korea College of Medicine, Seoul, Korea
}

\section{Study Design: A retrospective study.}

Purpose: To elucidate the causes of late revision following bone cement augmentation for osteoporotic vertebral compression fractures (OVCFs).

Overview of Literature: Percutaneous vertebroplasty (PVP) or kyphoplasty (KP) is thought to be effective for the treatment of OVCFs. Many complications related to PVP or KP have been reported. However, there is a paucity of reports regarding the causes of late revision surgery after failed PVP or KP.

Methods: Twenty six patients who developed unremitted back pain and/or progressive neurological deficit after a symptom-free period since treatment with PVP or KP were enrolled. All patients underwent cement removal and anterior reconstruction. Among the 26 patients, 22 patients underwent anterior interbody fusion combined with posterior instrumentation; 4 patients underwent anterior reconstruction only. The causes of revision surgery were assessed. Clinical results were assessed using a visual analogue scale (VAS) and Oswestry Disability Index (ODI). The complications were analyzed.

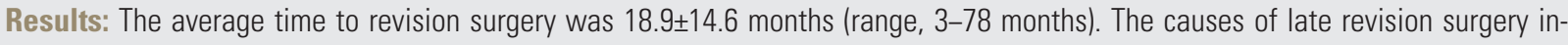
cluded 6 late infections, 8 progressive kyphoses, 10 proximal fractures after instrumented lumbar fusions, and 2 late neurological involvement. During the mean follow-up period of $13.5 \pm 7.8$ months, pre-revision mean VAS $(8.5 \pm 0.9)$ and ODI $(81.2 \pm 12.5)$ were improved to $4.2 \pm 1.4$ and $54.8 \pm 17.6$, respectively. Five patients $(19 \%)$ had serious complications after revision surgery.

Conclusions: This study presents complications of PVP or KP in the treatment of OVCFs although PVP or KP can be an effective treatment strategy for OVCF when applied in highly selected patients.

Keywords: Osteoporosis; Spinal fractures; Vertebroplasty; Surgical revision

\section{Introduction}

Percutaneous vertebroplasty (PVP) was introduced by Galibert et al. [1] and has been used to treat patients with osteoporotic vertebral compression fractures (OVCFs), vertebral metastatic cancer, myeloma and hemangioma, all of which cause severe pain. A success rate of $90 \%$ to $95 \%$ has been claimed for managing OVCFs with this treatment $[2,3]$. However, PVP is not a risk- or complication-free procedure, even though it is simple and effective for OVCFs in the elderly. Many complications related to PVP have been reported since its introduction. Periop-

Received May 10, 2013; Revised Aug 22, 2013; Accepted Aug 23, 2013

Corresponding author: Young-Hoon Kim

Department of Orthopaedic Surgery, Seoul St. Mary's Hospital, The Catholic University of Korea College of Medicine,

222 Banpo-daero, Seocho-gu, Seoul 137-701, Korea

Tel: +82-2-2258-6118, Fax: +82-2-535-9834, E-mail: boscoa@catholic.ac.kr 
Table 1. Patients' demographics

\begin{tabular}{|c|c|c|c|c|c|c|c|c|c|}
\hline $\begin{array}{l}\text { Case } \\
\text { No. }\end{array}$ & $\begin{array}{c}\text { Age }(y r) / \\
\text { Sex }\end{array}$ & $\begin{array}{l}\text { Bone cement } \\
\text { augmented } \\
\text { level }\end{array}$ & Category & $\begin{array}{l}\text { KP } \\
\text { or } \\
\text { PVP }\end{array}$ & $\begin{array}{c}\text { Initial BMD } \\
\text { (mean T-score) }\end{array}$ & $\begin{array}{l}\text { Time to } \\
\text { revision } \\
\text { (mo) }\end{array}$ & $\begin{array}{c}\text { Cement } \\
\text { pattern/IVC }\end{array}$ & $\begin{array}{l}\text { Revision } \\
\text { surgery }\end{array}$ & Remarks \\
\hline 1 & $75 / \mathrm{M}$ & D12 & $\mathrm{LI}$ & PVP & -3.1 & 6 & Trabecular/- & $\mathrm{AP}$ & Staphylococcus aureus \\
\hline 2 & $69 / \mathrm{M}$ & L1 & $\mathrm{LI}$ & PVP & -4.0 & 3 & Trabecular/- & $\mathrm{AP}$ & Escherichia coli \\
\hline 3 & $71 / F$ & L1, L2 & $\mathrm{LI}$ & KP & -3.8 & 13 & Solid/- & AP & Staphylococcus aureus \\
\hline 4 & $70 / F$ & L1 & $\mathrm{LI}$ & PVP & -4.8 & 8 & Trabecular/- & AP & Staphylococcus aureus \\
\hline 5 & $63 / \mathrm{M}$ & D11 & LI & PVP & -3.2 & 4 & Trabecular/- & AP & Staphylococcus aureus \\
\hline 6 & $62 / F$ & $\mathrm{D} 12$ & $\mathrm{LI}$ & PVP & -3.1 & 5 & Trabecular/- & AP & Staphylococcus aureus \\
\hline 7 & $61 / F$ & L1 & PK & PVP & -3.0 & 17 & Solid/+ & AP & \\
\hline 8 & $58 / F$ & $\mathrm{D} 12$ & PK & $\mathrm{KP}$ & -3.2 & 14 & Solid/- & AP & Subsequent fracuture+ \\
\hline 9 & $62 / F$ & D11 & PK & PVP & -3.1 & 31 & Solid/+ & $\mathrm{AP}$ & Subsequent fracuture+ \\
\hline 10 & $68 / F$ & L1 & PK & PVP & -3.6 & 15 & Solid/- & AP & \\
\hline 11 & $65 / F$ & $\mathrm{D} 12$ & PK & PVP & -3.5 & 13 & Solid/+ & AP & Subsequent fracuture+ \\
\hline 12 & $62 / F$ & L1 & PK & PVP & NA & 29 & Solid/- & AlF & \\
\hline 13 & $59 / F$ & $\mathrm{D} 10$ & PK & PVP & -3.2 & 18 & Solid/+ & AP & Subsequent fracuture+ \\
\hline 14 & $63 / F$ & D12 & PK & PVP & -3.8 & 23 & Solid/- & $\mathrm{AP}$ & \\
\hline 15 & $62 / F$ & $\mathrm{D} 11$ & PF & PVP & -3.5 & 13 & Solid/+ & AlF & L1-5 Fusion state \\
\hline 16 & $69 / F$ & D10 & PF & $\mathrm{KP}$ & -4.2 & 13 & Solid/+ & $\mathrm{AP}$ & L2-5 Fusion state \\
\hline 17 & $64 / F$ & L1 & PF & PVP & -3.0 & 24 & Solid/+ & $A P$ & L2-4 Fusion state \\
\hline 18 & $61 / F$ & D12 & PF & PVP & -4.2 & 18 & Solid/+ & AlF & L1-5 Fusion state \\
\hline 19 & $63 / F$ & D10 & PF & PVP & -3.5 & 32 & Solid/+ & AlF & L1-5 Fusion state \\
\hline 20 & $63 / F$ & L1 & PF & PVP & -3.4 & 13 & Solid/+ & $\mathrm{AP}$ & L2-4 Fusion state \\
\hline 21 & $62 / F$ & $\mathrm{D} 12$ & PF & $\mathrm{KP}$ & -3.1 & 32 & Solid/+ & AP & L2-4 Fusion state \\
\hline 22 & $60 / F$ & L1 & PF & PVP & NA & 78 & Trabecular/- & AP & L2-4 Fusion state \\
\hline 23 & $61 / F$ & L1 & PF & PVP & -3.8 & 24 & Solid/+ & AP & L2-4 Fusion state \\
\hline 24 & $62 / F$ & D12 & PF & KP & -3.5 & 16 & Trabecular/- & $\mathrm{AP}$ & L1-5 Fusion state \\
\hline 25 & $58 / F$ & D10 & $\mathrm{LN}$ & PVP & -3.6 & 15 & Solid/+ & AP & \\
\hline 26 & $65 / F$ & L1 & LN & PVP & -3.7 & 14 & Solid/- & AP & \\
\hline
\end{tabular}

KP, kyphoplasty; PVP, percutaneous vertebroplasty; BMD, bone mineral density; IVC, intravertebral cleft; LI, late infection; $A P$, antero-posterior fusion; PK, progressive kyphosis; NA, not available; AIF, anterior interbody fusion; PF, proximal fractures after instrumented fusions; LN, late neurologic deficit.

erative complications related to PVP or kyphoplasty (KP) are rare; however, when they occur, they can be devastating [4-6]. Most perioperative or intraoperative complications associated with PVP or KP reported in the literature include neurologic complications by extravasation of the cements, pulmonary emboli, rib fractures, and infection.

The incidence of acute clinical complications varies, but is reported to be $1.3 \%$ [7]. For minor complications, however, symptomatic treatment may be sufficient; however, for major complications, revision surgery should be performed with inevitable great morbidity in the elderly.
The incidence and causes of late clinical complications that require surgical intervention are not well known and are likely underreported, although late revision surgery for late spondylitis, progressive kyphosis and late subsequent refractures has been reported [8-10]. Therefore, the purpose of this study was to investigate the causes of late revision after cement augmentation for OVCFs. However, this study does not support the argument against PVP or KP for OVCFs. 


\section{Materials and Methods}

The study was performed after obtaining institutional review board (IRB approval N. KC12RISI0016) approval for retrospective chart review and outcome assessment. Retrospective cohort data were obtained for a consecutive series of patients who underwent revision surgery following PVP or KP for osteoporotic spinal fracture between July 2000 and December 2010 in our single institute. Among these data, patients with the following exclusion criteria were excluded; 1) revision surgery for immediate peri operative and intraoperative complications such as bone cement leakage, embolism or neurologic complications and 2) other pathologic conditions such as metastasis or multiple myeloma. Twenty-six patients were enrolled. Major symptoms leading revision surgery were uncontrolled mechanical back pain with or without neurological symptoms. The mean age of the cohort was $63 \pm 4.2$ years (range, $58-75$ years). Three men and 23 women were enrolled. All revision surgeries were performed by one senior surgeon. The mean follow-up period was $13.5 \pm 7.8$ months (range, 1-28 months). All pre-PVP or KP, and pre-revision magnetic resonance images (MRIs) were re-assessed by the authors and the spine radiologists to assess the cause of revision surgery. Patients were divided into 4 groups: 1) late infection, 2) progression of local kyphosis, 3) PVP or KP for proximal fracture after instrumented fusion, and 4) late neurological involvement without history of injury (Table 1). The symptom-free period after initial PVP or KP ranged from

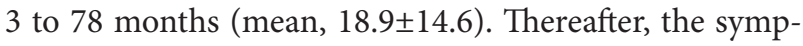
toms aggravated and the patients required hospitalization for pain relief. Five patients underwent KP, and 21 patients underwent PVP. The thoracolumbar junction (85\%) was the most commonly involved site. The involved levels were as follows; 11 L1, 8 T12, 3 T11, and 4 T10. During the follow-up period for evaluation before revision surgery, all patients had a history of medical treatment for osteoporosis. Of the 26 patients who underwent revision surgery, all patients underwent anterior reconstruction: 22 patients underwent combined posterior instrumentation (PI) and 4 patients underwent anterior interbody fusion (AIF) alone with or without a mesh cage.

For radiologic assessment, progression of kyphosis was evaluated by measuring the changes in the kyphotic angle using Cobb's method. Distribution patterns of the cement were classified as trabecular or solid opacification according to the criteria of Lane et al. [11]. Vertebral height was measured by the method of McKiernan et al. [12]. The height ratio of the anterior and posterior aspects of the vertebral body and that of the middle and posterior vertebral heights for peri-cement bone resorption were calculated. The intravertebral cleft (IVC) was investigated with MRI before PVP or KP. However, progression of
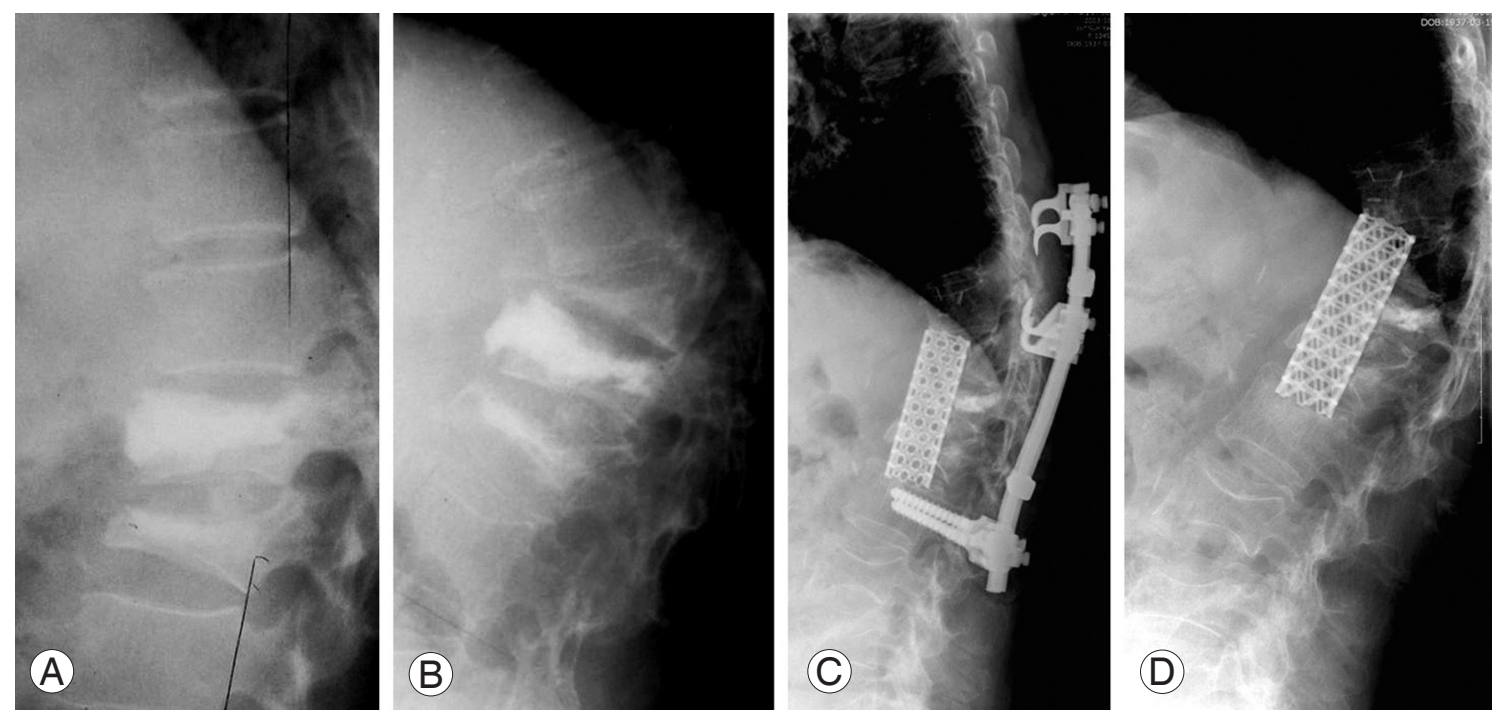

Fig. 1. (A) PVP was performed for T11 and T12 compression fractures. (B) Subsequent refracture with severe angular kyphosis and IVC developed after 10 months of PVP. (C) Although anterior interbody fusion using a mesh cage with posterior instrumentation was performed, metallic loosening was inevitable. (D) At 27 months after removal of posterior instrumentation. PVP, percutaneous vertebroplasty; IVC, intravertebral cleft. 
kyphosis, distribution patterns of bone cement and pericement bone resorption were not investigated for patients in the misdiagnosis, late infection and late neurological involvement groups.

For clinical results assessment, a visual analogue scale (VAS) and Oswestry Disability Index (ODI) were compared with statistical analysis (Student $t$-test). Operative complications were also analyzed.

\section{Results}

\section{Late infection}

Late infection was developed at the augmented segment in 6 patients. The mean interval from PVP or KP to the diagnosis of infection was 6.5 months (range, 3-13 months). All patients underwent AIF combined with PI. Causative organisms were identified in all patients (1 Escherichia coli and 5 Staphylococcus aureus).

\section{Progressive kyphosis}

Eight patients were included the progressive local kyphosis group. The mean kyphosis measured was $16.9^{\circ} \pm 9.9^{\circ}$ (range, $8^{\circ}-33.6^{\circ}$ ) after cement augmentation and $36.3 \pm 4.6$ (range, 28.6-42) just before revision surgery. The causes of progressive kyphosis were subsequent fracture at the proximal segment in 4 patients (Fig. 1) and resorption of bone around the bone cement in 4 patients with IVC on MRI. All the 4 patients with resorption of bone around the cement showed a solid type.

\section{Proximal fractures after instrumented lumbar fusions}

Ten patients were enrolled in this group for proximal or adjacent segments fracture (Figs. 2, 3). Of the 10 patients, 8 patients showed IVCs on pre-revision MRIs. The mean kyphosis measured $17.9^{\circ} \pm 8.9^{\circ}$ after PVP or KP and $29.3^{\circ} \pm 9.8^{\circ}$ before revision surgery. The mean anterior and posterior vertebral height ratio measured $0.6 \pm 0.2$ after PVP or KP and $0.5 \pm 0.2$ before revision surgery. The mean preoperative middle and posterior vertebral height ratios measured $0.5 \pm 0.1$ after PVP or KP and $0.4 \pm 0.2$ before revision surgery.

\section{Late neurological involvement}

Two patients exhibited late neurological involvement. Neurologic impairments developed insidiously (mean revision time 14.5 months). Displacement of the fracture fragment from the augmented segments and dynamic instability were the leading causes of neurologic impairments. Both patients underwent revision surgery with anterior decompression and reconstruction with or with-
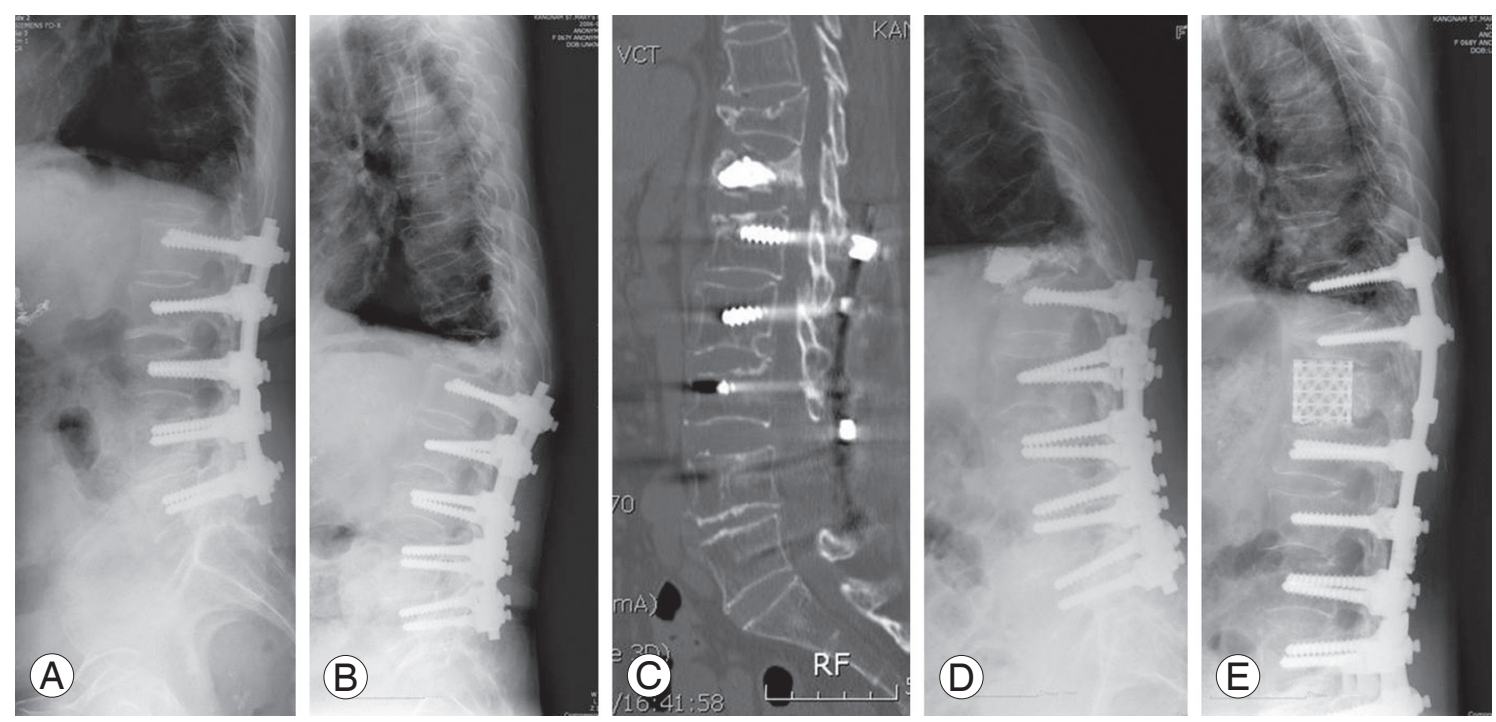

Fig. 2. (A) This 61-year-old female patient underwent instrumented lumbar fusion 10 years ago. (B) T12 compression fracture developed 5 years after instrumented fusion. (C) Computed tomography shows solid opacification without interdigitation of the bone cement. (D) Shows retropulsion of fracture fragments into the spinal canal with local kyphosis. (E) Anterior decompression with a mesh cage and posterior instrumentation were performed. 
out PI, respectively.

\section{Clinical results}

The pre-revision mean VAS and ODI were $8.5 \pm 0.9$ and $81.2 \pm 12.5$, respectively. At last follow-up, the mean VAS and ODI were $4.2 \pm 1.4$ and 54.8 \pm 17.6 , respectively. These clinical outcomes showed a statistical significance $(p<0.05)$. Major complication was metallic failure. Four patients $(16 \%)$ required re-revision surgery for their metallic failure (Figs. 1, 3). Of the 26 patients who underwent revision surgery, one immunocompromised patient died of sepsis postoperatively.

\section{Discussion}

Late causes of revision surgery for complications related to PVP or KP have rarely been reported [8-10]. In our series, major causes of revision surgery were infection, progressive kyphosis and proximal segment fracture following previous instrumented fusion. Among these causes, late infection developed in 6 patients at 3 to 25 months postoperatively after PVP or KP. Yu et al. [13] reported 1 infection among 200 PVP cases, whereas Kallmes et al. [14] reported 1 infection among 63 cases. Shin et al. [8] reported $1.9 \%$ postoperative pyogenic spondylitis after PVP or KP. Infection following PVP or KP has underscored the possibility of devastating, albeit rare, complications. Although pyogenic spondylitis has a low prevalence rate, the risk appears to be increased in patients who are immunocompromised, in poor general condition, or in those who have coexistent comorbidities [8]. Out of our 6 patients, 4 patients had serious medical comorbidities: uncontrolled diabetes mellitus in 3 patients and renal cancer treated with anticancer chemotherapy in 1 patient. During revision surgery, we tried to remove all the cement in the vertebral body since the remaining cement can act as a foreign body. However, one patient who suffered from renal cancer and was undergoing chemotherapy died of sepsis. This patient's OVCF was not related to a metastatic pathological fracture. It is critical that spine surgeons be aware of late infection after PVP or KP. Eight patients were included in the progression of local kyphosis group. The causes of progressive local kyphosis in this study were subsequent re-fractures at the adjacent segments in 4 patients and resorption of bone around the cement in 4 patients. The risk of re-fracture in adjacent segments seems to be increased after PVP or KP. Lee et al. [6] reported that $18 \%$ of their patients in the VP group and $17 \%$ in the KP group showed subsequent fractures
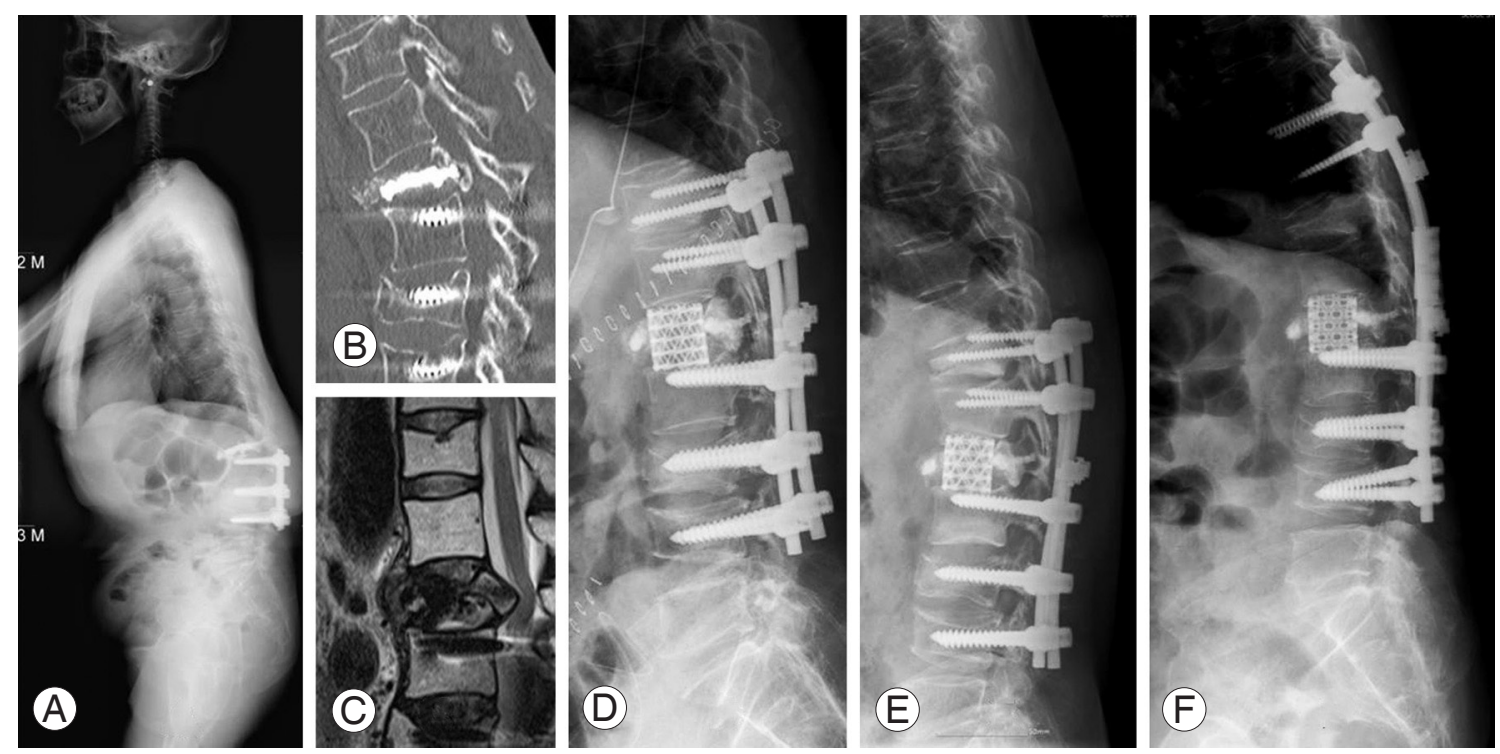

Fig. 3. (A) This 63-year-old female patient underwent instrumented lumbar fusion 8 years ago. L1 compression fracture developed and percutaneous vertebroplasty (PVP) was performed at another institute. After PVP, back pain subsided, but 4 months later, unremitted back pain with progressive kyphosis developed and she was transferred to our institute. (B, C) Magnetic resonance imaging and computed tomography show retropulsion of fracture fragment into the spinal canal, but neurological symptoms were not noted on her physical examination. (D) Anterior decompression with a mesh cage and posterior instrumentation were performed. (E) Refracture developed at the most upper implanted segment. (F) Re-revision surgery was performed. 
at another level. However, the natural history of OVCFs needs to be taken into consideration, as the risk of new fracture rises exponentially with an increasing incidence of fractures [15-17]. Reinforcement of adjacent vertebrae with cement can be done for new fractures $[18,19]$. Four patients needed revision surgery because of severe local kyphosis at subsequent re-fracture segments, which could not be anticipated in the restoration of local kyphosis after re-PVP or re-KP. Bone cement augmentation was performed at one level in all 4 patients. Therefore, we could not obtain any information about whether the number of augmented segments could influence or increase the incidence of subsequent re-fracture in this study. In another 4 patients, resorption of bone occurred around the cement. IVC may be an important factor related to the recollapse of previously treated vertebra after KP [20-25]. These 4 patients presented progressive collapse of the augmented vertebral body compared to immediate postoperative state. In addition, IVC on preoperative MRIs before PVP had been noted in all 4 patients. Eventually, revision surgery was needed.

The most common cause of late revision surgery in this study was proximal fracture after instrumented lumbar fusion. It is known that instrumented spinal fusion may make mechanical load shift and increase the incidence of the fracture at the adjacent segment to the fused segments. Moreover, this increased stress concentration at the adjacent segments may also result in increased stress at the non-filled cement augmented vertebra. In this consecutive series, out of 10 patients, the mean number of 3.9 segments were included in instrumented fusions. Eight patients showed IVC at the proximal or adjacent fracture segment. Patients with IVC showed progressive collapse of the vertebral body compared to those without IVC following the bone cement augmenatation procedures [20]. This was thought to be the cause of recollapse of the vertebral body in patients with proximal segment fractures with IVC; the stress shielding effect caused more osteoporosis of bone around the cement, resulting in bone resorption, and/or a stress riser around the bone cement by non-interdigitation of the cement. Progressive bone resorption and collapse of the vertebral body was aggravated by stress concentration at the adjacent segment after cement augmentation.

Two patients developed thoracic myelopathy with myelopathic gait. Fracture fragments treated with PVP were retropulsed into the spinal canal with collapse of the vertebral body. Ha et al. [9] also suggested that progressive collapse of an augmented vertebral body could be the cause of neurological complications after PVP or KP. These two cases in the present study had a history of a symptom-free period after PVP. Myelopathy then developed without a history of injury. Plain radiographs showed resorption of bone surrounding the cement, resulting in retropulsion of the fracture fragments into the spinal canal. Anterior reconstruction using a mesh cage with PI in one patient and without PI in one patient was performed.

The limitation of this study includes a narrow focus of revision cases after PVP or KP. If conservative treatment cases had been included, the incidence of misuse, overuse, and complications may have been increased. Also, clinical outcomes after revision surgeries were not included. The limit cohort in this study does, however, provide a glimpse at the possible failures caused by misuse or overuse and complications of the PVP or KP in the treatment of OVCFs.

\section{Conclusions}

In conclusion, this study does not support the argument against PVP or KP for OVCFs, but presents possible complications of the PVP or KP in the treatment of OVCFs, although PVP or KP can be an effective treatment modality in a highly selected cohort of OVCFs patients.

\section{Conflict of Interest}

No potential conflict of interest relevant to this article was reported.

\section{Acknowledgments}

The authors wish to acknowledge the financial support of the Catholic Medical Center Research Foundation made in the program year of 2009.

\section{References}

1. Galibert P, Deramond H, Rosat P, Le Gars D. Preliminary note on the treatment of vertebral angioma by percutaneous acrylic vertebroplasty. Neurochirurgie 1987;33:166-8.

2. Barr JD, Barr MS, Lemley TJ, McCann RM. Percuta- 
neous vertebroplasty for pain relief and spinal stabilization. Spine (Phila Pa 1976) 2000;25:923-8.

3. Jensen ME, Evans AJ, Mathis JM, Kallmes DF, Cloft HJ, Dion JE. Percutaneous polymethylmethacrylate vertebroplasty in the treatment of osteoporotic vertebral body compression fractures: technical aspects. AJNR Am J Neuroradiol 1997;18:1897-904.

4. Lee BJ, Lee SR, Yoo TY. Paraplegia as a complication of percutaneous vertebroplasty with polymethylmethacrylate: a case report. Spine (Phila Pa 1976) 2002;27:E419-22.

5. Harrington KD. Major neurological complications following percutaneous vertebroplasty with polymethylmethacrylate : a case report. J Bone Joint Surg Am 2001;83:1070-3.

6. Lee MJ, Dumonski M, Cahill P, Stanley T, Park D, Singh K. Percutaneous treatment of vertebral compression fractures: a meta-analysis of complications. Spine (Phila Pa 1976) 2009;34:1228-32.

7. Chiras J, Depriester C, Weill A, Sola-Martinez MT, Deramond H. Percutaneous vertebral surgery: technics and indications. J Neuroradiol 1997;24:45-59.

8. Shin JH, Ha KY, Kim KW, Lee JS, Joo MW. Surgical treatment for delayed pyogenic spondylitis after percutaneous vertebroplasty and kyphoplasty: report of 4 cases. J Neurosurg Spine 2008;9:265-72.

9. Ha KY, Kim KW, Kim YH, Oh IS, Park SW. Revision surgery after vertebroplasty or kyphoplasty. Clin Orthop Surg 2010;2:203-8.

10. Miyagi R, Sakai T, Bhatia NN, Sairyo K, Katoh S, Chikawa T. Anterior thoracolumbar reconstruction surgery for late collapse following vertebroplasty: report of three cases. J Med Invest 2011;58:148-53.

11. Lane JI, Maus TP, Wald JT, Thielen KR, Bobra S, Luetmer PH. Intravertebral clefts opacified during vertebroplasty: pathogenesis, technical implications, and prognostic significance. AJNR Am J Neuroradiol 2002;23:1642-6.

12. McKiernan F, Faciszewski T, Jensen R. Reporting height restoration in vertebral compression fractures. Spine (Phila Pa 1976) 2003;28:2517-21.

13. Yu SW, Chen WJ, Lin WC, Chen YJ, Tu YK. Serious pyogenic spondylitis following vertebroplasty: a case report. Spine (Phila Pa 1976) 2004;29:E209-11.

14. Kallmes DF, Schweickert PA, Marx WF, Jensen ME. Vertebroplasty in the mid- and upper thoracic spine. AJNR Am J Neuroradiol 2002;23:1117-20.
15. Mehbod A, Aunoble S, Le Huec JC. Vertebroplasty for osteoporotic spine fracture: prevention and treatment. Eur Spine J 2003;12 Suppl 2:S155-62.

16. Perez-Higueras A, Alvarez L, Rossi RE, Quinones D, Al-Assir I. Percutaneous vertebroplasty: long-term clinical and radiological outcome. Neuroradiology 2002;44:950-4.

17. Grados F, Depriester C, Cayrolle G, Hardy N, Deramond $\mathrm{H}$, Fardellone P. Long-term observations of vertebral osteoporotic fractures treated by percutaneous vertebroplasty. Rheumatology (Oxford) 2000;39:1410-4.

18. Gaughen JR Jr, Jensen ME, Schweickert PA, Marx WF, Kallmes DF. The therapeutic benefit of repeat percutaneous vertebroplasty at previously treated vertebral levels. AJNR Am J Neuroradiol 2002;23:165761.

19. Yoon ST, Qureshi AA, Heller JG, Nordt JC, 3rd. Kyphoplasty for salvage of a failed vertebroplasty in osteoporotic vertebral compression fractures: case report and surgical technique. J Spinal Disord Tech 2005;18 Suppl:S129-34.

20. Ha KY, Lee JS, Kim KW, Chon JS. Percutaneous vertebroplasty for vertebral compression fractures with and without intravertebral clefts. J Bone Joint Surg Br 2006;88:629-33.

21. Shin DA, Kim KN, Shin HC, Kim SH, Yoon DH. Progressive collapse of PMMA-augmented vertebra: a report of three cases. Zentralbl Neurochir 2008;69:436.

22. Kim YY, Rhyu KW. Recompression of vertebral body after balloon kyphoplasty for osteoporotic vertebral compression fracture. Eur Spine J 2010;19:1907-12.

23. Abdel-Wanis ME, Solyman MT, Hasan NM. Sensitivity, specificity and accuracy of magnetic resonance imaging for differentiating vertebral compression fractures caused by malignancy, osteoporosis, and infections. J Orthop Surg (Hong Kong) 2011;19:14550.

24. Baur A, Stabler A, Bruning R, et al. Diffusion-weighted MR imaging of bone marrow: differentiation of benign versus pathologic compression fractures. Radiology 1998;207:349-56.

25. Tan DY, Tsou IY, Chee TS. Differentiation of malignant vertebral collapse from osteoporotic and other benign causes using magnetic resonance imaging. Ann Acad Med Singapore 2002;31:8-14. 